Research Article

\title{
Valorization of Albedo Orange Peel Waste to Develop Electrode Materials in Supercapacitors for the Electric Industry
}

\author{
Gladis G. Suárez $\mathbb{D}^{1,2}$ José A. Ramírez $\mathbb{D}^{3}{ }^{3}$ Juan F. Castañón $\mathbb{D}^{3}{ }^{3}$ Jorge A. Galavíz $\mathbb{D}^{4}{ }^{4}$ \\ and Perla C. Meléndez ${ }_{(D)}^{5}$ \\ ${ }^{1}$ Centro de Excelencia, Universidad Autónoma de Tamaulipas, Centro Universitario, 87120 Cd. Victoria, Tamaulipas, Mexico \\ ${ }^{2}$ Universidad Politécnica de Victoria, Parque Científico y Tecnológico de Tamaulipas, 87138 Cd. Victoria, Tamaulipas, Mexico \\ ${ }^{3}$ Unidad Académica de Trabajo Social y Ciencias para El Desarrollo Humano, Universidad Autónoma de Tamaulipas, \\ Centro Universitario, $87120 \mathrm{Cd}$. Victoria, Tamaulipas, Mexico \\ ${ }^{4}$ Universidad Juárez Autónoma de Tabasco, Av. Universidad s/n Magisterial, 86040 Villahermosa, Tabasco, Mexico \\ ${ }^{5}$ Centro de Investigación y de Estudios Avanzados Del Instituto Politécnico Nacional, Zona Industrial 25900, \\ Ramos Arizpe, Coahuila, Mexico
}

Correspondence should be addressed to Gladis G. Suárez; gsuarezv@upv.edu.mx

Received 6 August 2021; Revised 10 November 2021; Accepted 16 November 2021; Published 10 December 2021

Academic Editor: Ana Angelica Feregrino-Perez

Copyright (c) 2021 Gladis G. Suárez et al. This is an open access article distributed under the Creative Commons Attribution License, which permits unrestricted use, distribution, and reproduction in any medium, provided the original work is properly cited.

\begin{abstract}
This work proposes the use of albedo of orange peel in generation of carbon for applications in supercapacitors. For this, a comparison of compositional and electrochemical properties present in the carbons obtained of albedo, flavedo, and the complete orange peel was carried out. The morphology and composition of carbons obtained were analyzed by Field Emission Scanning Electron Microscopy (FESEM), Energy Dispersive X-ray (EDX), X-Ray Diffraction (XRD), and Fourier-transform infrared spectroscopy (FT-IR). The synthetized carbons were not subjected to the activation process by chemical compounds to relate only the properties of orange peel parts with their electrochemical behaviour. All samples were tested by cyclic voltammetry $(\mathrm{CV})$ and electrochemical impedance spectroscopy (EIS). The carbon obtained of albedo presented a superior specific capacitance (210 F/g) of the rest samples. The value of albedo-based carbon capacitance is comparable with works presented in the literature that used a whole orange peel with chemical activators. In this way, it is possible to obtain large capacitances using only a part of orange peel (albedo). Thus, the importance of this study is that the albedo can be proposed as a material applied to electrodes for supercapacitors while the flavedo can be used in food industry or for oil extraction.
\end{abstract}

\section{Introduction}

A big percent of electricity generation in the world depends on fossil fuels. In Mexico, the power plants based on fossil fuels reached $79 \%$ of all installed plants in 2019 [1]. However, due to the depletion of fossil fuels, the countries are trying to deliver electricity based on other types of generation. So, the incorporation of alternative energies such as wind, solar, and hydrogen energy has been proposed to be incorporated on microgrids and grids of the electric industry. Even though the alternative energies are a good option, these have a random behavior that requires devices that store energy when it is excessive and deliver it when is necessary. The Energy Storage Systems (ESSs) mostly used are the batteries and supercapacitors [2].

The supercapacitor has the advantage of long cycle life and low cost, and its operation does not cause pollution [2]. Energy storage in supercapacitors is carried out using electrostatic charge accumulation or employing faradic reactions of electroactive species [3]. These devices are constituted by two electrodes (anode and cathode), an electrolyte, and a separator to isolate the electrodes [4]. Electrodes for supercapacitors based on activated carbon have been proposed due to their good electrical properties 
and moderate cost and the exploitation of the valorization of organic waste [3]. In this way, several works have reported the synthesis of carbon obtained from organic products, such as sorghum pith [5], banana peel [6], and grapefruit peel [7], where these products are used completely to obtaining carbon with no opportunity to use another part of their waste for another use.

On the other hand, world orange production this year is expected to be approximately 49.4 million tons. According to the USDA, Mexico ranks 2nd in orange production with approximately 4,737 thousand tons per year $[8,9]$. These are mainly used in the production of jams, flavoring, and juices. The high demand for orange for such products brings a high generation of waste consisting mainly of its peels that constitute $50-60 \%$ wt of the processed fruit [10]. Several works have proposed using whole orange peel to obtain activated carbon for energy storage applications in capacitors. These works highlight their carbon syntheses methods, such as hydrothermal carbonization and one-step [11, 12] and two-step pyrolysis $[13,14]$, as well as the use of various activators such as $\mathrm{ZnCl}_{2}$ and $\mathrm{KOH}[11,12], \mathrm{H}_{3} \mathrm{PO}_{4}$ [15], and $\left(\mathrm{Cu}_{2}(\mathrm{OH})_{2} \mathrm{CO}_{3}\right)[12]$.

According to previous information, it is important to take into account that orange peel is composed of a soft white part called mesocarp or albedo (15-25\%) and a bright orange outer pate known as flavedo (8-10\%) [16]. Albedo is mainly constituted by pectin and $62.5 \%$ of cellulose and flavonoids. In comparison, the flavedo is formed by oil glands and pigments or carotenoids [17]. In the literature, works have been found that have used flavedo or albedo to elaborate material applied to supercapacitors $[17,18]$. One of those, orange peel flavedo, was subjected to carbonization in an inert atmosphere and then activated utilizing $\mathrm{HCl}, \mathrm{HCl}$, and $\mathrm{H}_{2} \mathrm{SO}_{4}$ to improve its capacitance [17]. From these experiments, it was found that the highest capacitance obtained by CV (Cyclic Voltammetry) $(92 \mathrm{~F} / \mathrm{g}$ ) was provided by $\mathrm{H}_{3} \mathrm{PO}_{4}$ [17], while in another work, the use of all orange components for the construction of a capacitor is proposed [18].

The whole orange peel was carbonized in a single step in the anode $(186 \mathrm{~F} / \mathrm{g})$; hydrothermal carbonization was performed to the whole orange peel with $\mathrm{MnO}_{2}$ to synthesize the cathode. At the same time, the albedo was used as a separator between the electrodes. Since few works report the use of orange peel albedo and flavedo and the composition of grapefruit peel is similar, studies of grapefruit albedo with good capacitive characteristics have been found focusing on the activator $[19,20]$. Such is the case of [17], where an electrode based on grapefruit albedo doped with nitrogen and $\mathrm{CaCl}_{2}$ was obtained, reaching $245 \mathrm{~F} / \mathrm{g}$, as well as the work in [20], where carbon for electrode through a carbonization process in two steps and $\mathrm{KOH}$ reaching $292 \mathrm{~F} / \mathrm{g}$ of specific capacitance were was obtained.

From that mentioned above, it can be concluded that due to the abundance of orange in the world, several authors have proposed its whole peel for the production of carbon and use in supercapacitors [11-15]. Only few works have used flavedo of orange peel as a material for electrodes, focusing their attention on the utilized activators [19, 20]. However, no studies have been carried out on the capacitive behaviour of albedo. In this way, we propose to carry out a comparative study of the capacitive behavior of carbon obtained from whole peel, albedo, and flavedo focusing only on their qualities developed after of the carbonization process. The aim was to permit the use of the part with the best capacitances (albedo) in the industry of electric storage energy and the remaining in the food industry or obtaining oil.

\section{Materials and Methods}

2.1. Raw Material Preparation. The carbons used in this work were derivated from albedo, the flavedo, and the complete peel of orange (Citrus sinensis L.). The raw material (orange peel) was collected from local beverage businesses in Cd. Victoria, Tamaulipas, Mexico. The fruit pulp residue was discarded, while the raw material was washed with soap and water, and it was sun-dried for $48 \mathrm{~h}$. Subsequently, half of the material was conserved whole, and the other half was separated into its albedo (external portion which confers color to the peel) and flavedo (soft internal portion) components. Following this, the three portions were cyclically washed with deionized water (Fermont mark, Mexico) and ethyl alcohol (Innovating Science mark, U.S.A.) three times [21]. The samples were left to dry at room temperature and dehydrated in a muffle at $130^{\circ} \mathrm{C}$ for 2 hours. Once dehydrated, the samples were stored until their use.

2.2. Preparation of Orange Carbon. The complete orange peel (OPC), albedo (AC), and flavedo (FC) were converted in carbon in a muffle by a thermal process without an inert atmosphere. During the process, oxygen limitation is made through crucibles arrangement and sand (composed of $\mathrm{SiO}_{2}$ and $\mathrm{CaO}$ ) which allows at $1000^{\circ} \mathrm{C}$ by 60 minutes. In this process, chemical activators were not used; this synthesis was realized by duplicated.

\subsection{Physical and Morphologic Characterization.} Morphology of OPC, AC, and FC was studied with a Field Emission SEM-Philips XL-30 (Eindhoven, the Netherlands) equipment. An SEM/EDX (Philips XL30 series) was used with $20 \mathrm{kV}$ as working voltage using copper holders for the elemental composition. The crystalline structure was determined by X-Ray Diffraction (DRX) with a Philips-X'Pert Pro diffractometer (Eindhoven, the Netherlands); for these tests, a source of $\mathrm{CuK} \alpha(\lambda=0.1542 \mathrm{~nm})$ at $40 \mathrm{kV} 30 \mathrm{~mA}$ of operation and a goniometer speed of $0.12 \%$ was used. The functional groups obtained were studied by fourier-transform infrared spectroscopy (FT-IR) with a WQF-510A Rayleigh FT-IR spectrometer (Beijing, China) equipment at $4000 \mathrm{~cm}^{-1}$ to $400 \mathrm{~cm}^{-1}$.

2.4. Electrochemical Behavior. The electrochemical tests (CV and EIS) were performed using a Gill AC (ACM Instruments, England) potentiostat through a three-electrode cell 
with $1 \mathrm{M}$ of $\mathrm{H}_{2} \mathrm{SO}_{4}$ as the electrolyte. $\mathrm{An} \mathrm{Ag} / \mathrm{AgCl}$ electrode as a reference, a graphite electrode as a counter electrode and as a working electrode, and a vitreous carbon coated with $10 \mu \mathrm{L}$ carbon prepared ink were used. The ink was prepared with a $5 \mathrm{mg}$ mix of carbon from each sample (OPC, AC, and FC), $5 \mu \mathrm{L}$ Nafion solution (Sigma-Aldrich) as a binder, and $5 \mathrm{~mL}$ of 2-propanol (Sigma-Aldrich) [22]. The cyclic voltammetry was carried out at speeds of the potential sweep of $10,15,20,25,30$, and $35 \mathrm{mV} / \mathrm{s}$ [23-26] in a window potential of $-0.2 \mathrm{mV}$ to $1.4 \mathrm{mV}$ [27]. The capacitance calculation through cyclic voltammetry was carried out with the following equation [13-28]:

$$
C_{p}=\frac{\int i d V}{2 m v \cdot V},
$$

where $\int i d V$ is the integrated area under the curve of VC, $m$ $(g)$ is the mass of the carbon, $\Delta V(V)$ is the window of potential applied to the test, and $v\left(V s^{-1}\right)$ is the potential sweep speed.

Electrochemical Impedance Tests (EISs) were performed at frequencies from 100,000 [29] to $0.06 \mathrm{~Hz}$ using the same cell for CV and electrodes. The results for the elemental composition to the EDS and electrochemical tests are represented as the means of two measurements performed independently, but no statistical analysis was performed.

\section{Results and Discussion}

3.1. Physical Characteristics of Carbons. Photographs of OPC, FC, and AC are observed in Figure 1. The porous aspect of them and the difference in their brightness can be easily observed. Figure 1(a) shows the OPC with a little porous aspect and an opaque tone. A brighter and porous aspect is observed in the AC (Figure 1(b)) concerning the carbon obtained from the complete peel. The albedo (Figure 1(c)) allowed obtaining a more opaque and porous carbon with respect to FC and OPC, respectively. Manipulating these carbons was more difficult than in the FC, which fell apart when touched with the hands.

\subsection{Morphology and Elemental Composition of Carbons.} Figure 2 shows the SEM analysis of orange fractions; irregular micrometer-size flakes [7], pores, and small particles on the flakes can be observed on these micrographs. The darkest spaces present in all figures can be due to the porous structure of the obtained material. This structure type favors a better conductivity because they allow greater diffusion of ions, which in turn improves the electrochemical behavior [30]. In the samples of OPC are observed white particles attributed to calcium compound. All the samples present similar aspects; however, in the AC, clearer flakes and holes are more defined.

The results of EDS made to carbons are deployed in Table 1, where the presence of carbon in all samples is evident. Another element found in high percentage was calcium. The composition of the parts of orange peel and the formation of ash are attributed to the combustion of a part of the sample. It is observed that the highest concentration of carbon is found in AC, followed by FC and OPC. In addition, it is observed that the concentration of $\mathrm{Ca}$ is the highest in OPC, followed by FC and AC.

3.3. Formation of Compounds. In Figure 3, the compositional analysis of the OPC, AC, and FC by X-ray diffraction is shown. This analysis has corroborated the presence of carbon and calcium as in EDS analysis. The peaks located at $26.1^{\circ}$ and $54.0^{\circ}$ correspond to the planes (002) and (004) of pristine graphite, rich in carbon $[31,32]$. The broad bands located between $2 \theta \sim 23^{\circ}$ and $2 \theta \sim 43^{\circ}$ are characteristic of the (002) and (100) planes of graphitized carbon [33, 34], which only is shown in the AC and FC. Also, the peak located at $23^{\circ}$ simultaneously overlaps with the (112) plane of the calcite. Other calcite planes such as (104), (114), (110), (113), (202), (018), (116), and (122) are located at $29.4^{\circ}, 32.8^{\circ}, 35.9^{\circ}, 39.4^{\circ}, 43.2^{\circ}, 47.3^{\circ}, 48.3^{\circ}$, and $57.3^{\circ}$, respectively, according to the chart (ICDD PDF 00-005-0586) [35-37]. The peaks located at $20.6^{\circ}, 34^{\circ}$, and $37.26^{\circ}$ were attributed to $\mathrm{Ca}(\mathrm{OH})_{2}$ (No: 164, PDF 00-004-0733)) $[38,39]$.

The formation of $\mathrm{CaCO}_{3}$ is the product of the reaction of calcium oxide present in the orange peel, flavedo, and albedo and $\mathrm{CO}_{2}$, reported at $930.4^{\circ} \mathrm{C}$, which obeys equation (2), while the reaction of $\mathrm{CaO}$ present in the peels with the water steam generated at temperatures higher than $930.4^{\circ} \mathrm{C}$ causes the formation of $\mathrm{Ca}(\mathrm{OH})_{2}$ obeying equation (3) [40].

$$
\begin{gathered}
\mathrm{CaO}_{(s)}+\mathrm{CO}_{2} \longrightarrow \mathrm{CaCO}_{3(s)}, \\
\mathrm{CaO}+\mathrm{H}_{2} \mathrm{O} \longrightarrow \mathrm{Ca}(\mathrm{OH})_{2} .
\end{gathered}
$$

3.4. Functional Groups on the Surface. The spectra of FTIR analysis performed to OPC, FC, and AC are shown in Figure 4. An intense peak at $1447 \mathrm{~cm}^{-1}$ and $874 \mathrm{~cm}^{-1}$ representing carbonate ion vibrations was observed in all the samples [41]. The peaks located at $2362 \mathrm{~cm}^{-1}$ are attributed to contamination on the surface [42]. The peak at $708 \mathrm{~cm}^{-1}$ and the band located approximately 3421 and $3419 \mathrm{~cm}^{-1}$ correspond to $\mathrm{O}-\mathrm{H}$ groups [43]. In addition to these peaks, for the OPC, short peaks situated at $2935 \mathrm{~cm}^{-1}, 2342 \mathrm{~cm}^{-1}$ contamination are identified. The peaks at $1242 \mathrm{~cm}^{-1}$ and $1041 \mathrm{~cm}^{-1}$ correspond to a C-O extension vibration $[44,45]$, while the peaks at $1731 \mathrm{~cm}^{-1}$ and $603 \mathrm{~cm}^{-1}$ are attributed to $\mathrm{O}-\mathrm{H}$ groups.

In the FC sample, the peak localized at $2935 \mathrm{~cm}^{-1}$ and $2342 \mathrm{~cm}^{-1}$ and $1731 \mathrm{~cm}^{-1}$ are vaporized, while the peak localized at $3421 \mathrm{~cm}^{-1}$ is smoothed. In this spectrum, the decrease of peaks at $2362 \mathrm{~cm}^{-1}$ corresponding to $\mathrm{CO} 2$ is noted [42]. Additionally, the intensity of peaks at $1041 \mathrm{~cm}^{-1}, 603 \mathrm{~cm}^{-1}$, and $874 \mathrm{~cm}^{-1}$ is attributed to $\mathrm{C}-\mathrm{O}$ extension vibration [45], O-H group [43], and carbonate ion vibrations, respectively [41], which are increased. The light increasing at peaks located at $708 \mathrm{~cm}^{-1}$ reflects the participation of $\mathrm{C}-\mathrm{C}$ as a simple bond in the $\mathrm{AC}$ sample, 


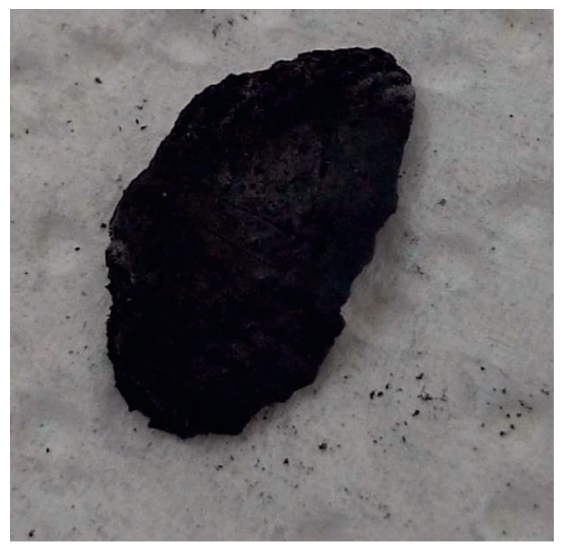

(a)

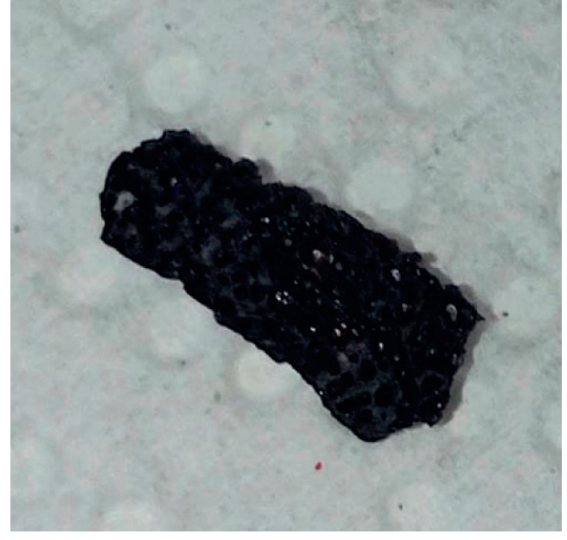

(b)

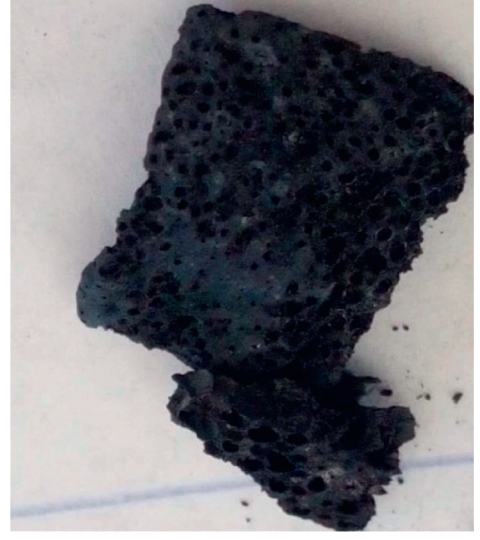

(c)

Figure 1: Aspect of the obtained carbon according to its source of origin. (a) OPC, (b) FC, and (c) AC.

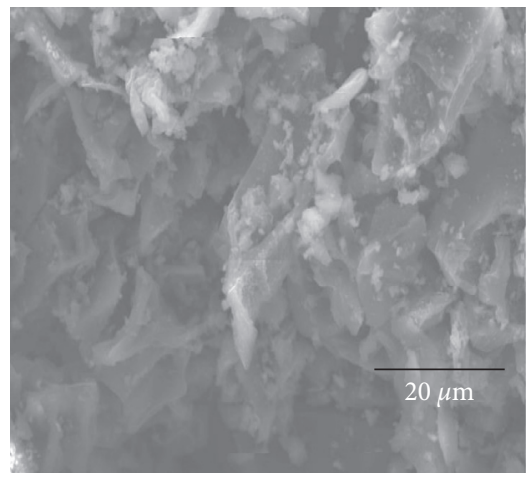

(a)

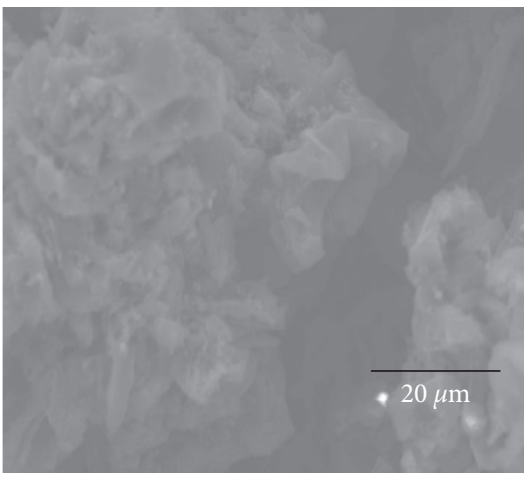

(b)

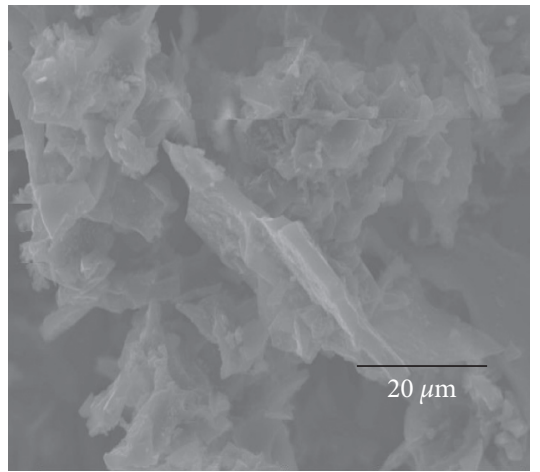

(c)

FIgUre 2: SEM images at 1000X of (a) OPC, (b) FC, and (c) $\mathrm{AC}$ at $1000^{\circ} \mathrm{C}$.

TABLE 1: Elemental composition according to the EDS of orange peel, flavedo, and albedo.

\begin{tabular}{lcccc}
\hline Samples & C & O & Ca & Others \\
\hline OPC & 64.3 & 5.5 & 24 & 6.2 \\
FC & 66.73 & 5.64 & 23.14 & 4.5 \\
AC & 78 & 5.66 & 15 & 1.34 \\
\hline
\end{tabular}

while the peak of $3419 \mathrm{~cm}^{-1}$ corresponding to $\mathrm{O}-\mathrm{H}$ groups is smoothed [44], the peaks at $2363 \mathrm{~cm}-1$ corresponded to CO2 [42] and 1441 and 874 assigned to carbonate ion vibration are maintained as in the other samples.

The oxygen functional groups found on the surface of samples improve the capacitive capacity in materials for supercapacitors and are highly hydrophilic that absorb water easily [46]. In addition, pseudocapacitance is provided by these functional groups in an aqueous acid electrolyte, which ensures the long-term cyclability of the electrodes [24]. In contrast, the hydroxyl/carbonyl groups have shown to well provide capacitance [47].
3.5. Electrochemical Characteristics. Figures 5(a)-5(c) display the VC of OPC, FC, and AC at speeds of 5, 10, 15, 20, 25,30 , and $35 \mathrm{mV} / \mathrm{s}$ [24-26]. The potentials shown in the voltagrams were converted to RHE for convenience. All the VC obtained profiles have semirectangular shapes typical of carbon capacitors [48]. This semirectangular shape is maintained with minimal distortion at higher scanning speeds, suggesting rapid transfer of charges without restrictions attributed to a combination of meso- and micropores [49]. Furthermore, a rectangular-shaped distortion can be observed, attributed to the redox reactions originated by the oxygen functional groups. The 


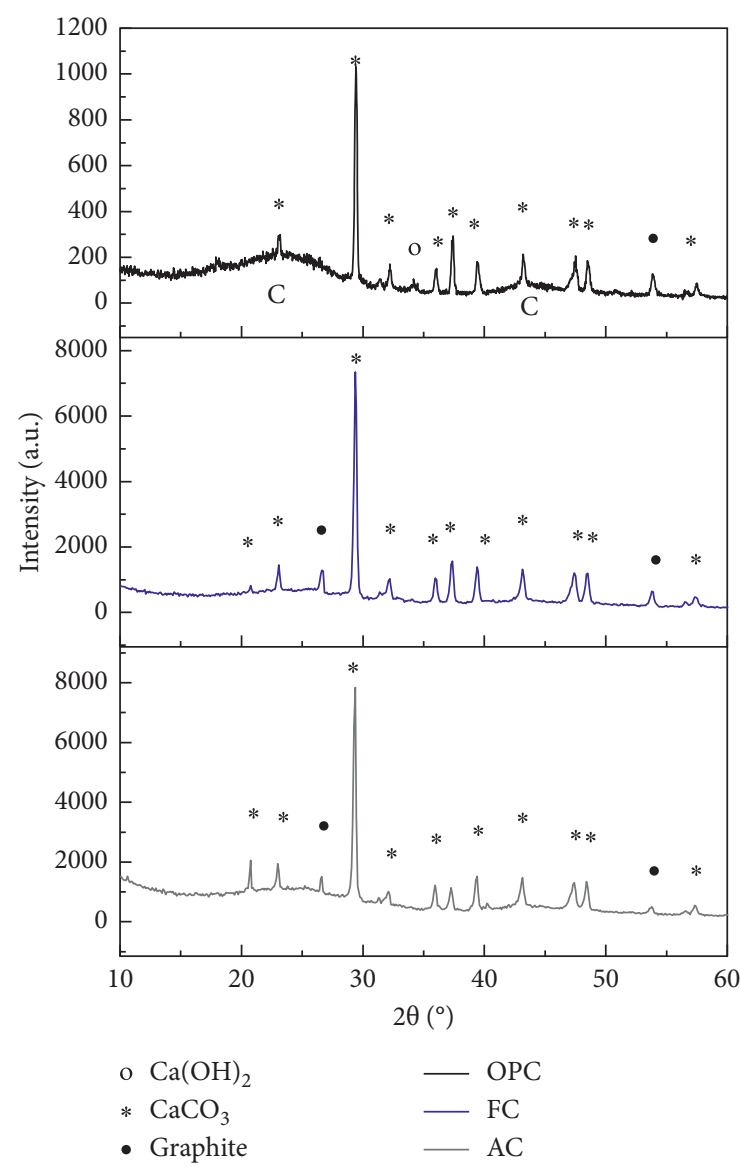

FIGURE 3: XRD patterns of orange fractions: orange peel, flavedo, and albedo.

capacitance presented in the material appears to be a contribution of the electrical double layer (EDLC) and pseudocapacitance [50]. The profiles remained above $1.1 \mathrm{~V}$, indicating that the material in a device can be safely operated at that potential [13].

Figure 5(d) compares the voltagrams of the three materials studied at $10 \mathrm{mV} / \mathrm{s}$. The gray line, belonging to the albedo, has a greater dimension of the curves, closely followed by the flavedo (black line) and well above the complete peel (blue line). A closer look at Figure 5(d) indicates more functionality as a capacitor material. The capacitances obtained at $10 \mathrm{mV} / \mathrm{s}$ were of $114.8 \mathrm{~F} / \mathrm{g}, 188.7 \mathrm{~F} / \mathrm{g}$, and $210.8 \mathrm{~F} / \mathrm{g}$ for complete OPC, FC, and AC.

Figure 6 shows the trend of capacitance values in the samples at speeds of 10 to $35 \mathrm{mV} / \mathrm{s}$. The highest capacitance values were obtained in the albedo samples, followed by flavedo and much lower in the peel samples. It can be seen that, in the three samples, the capacitance tended to decrease as the speed of the voltage increased. It is observed that the

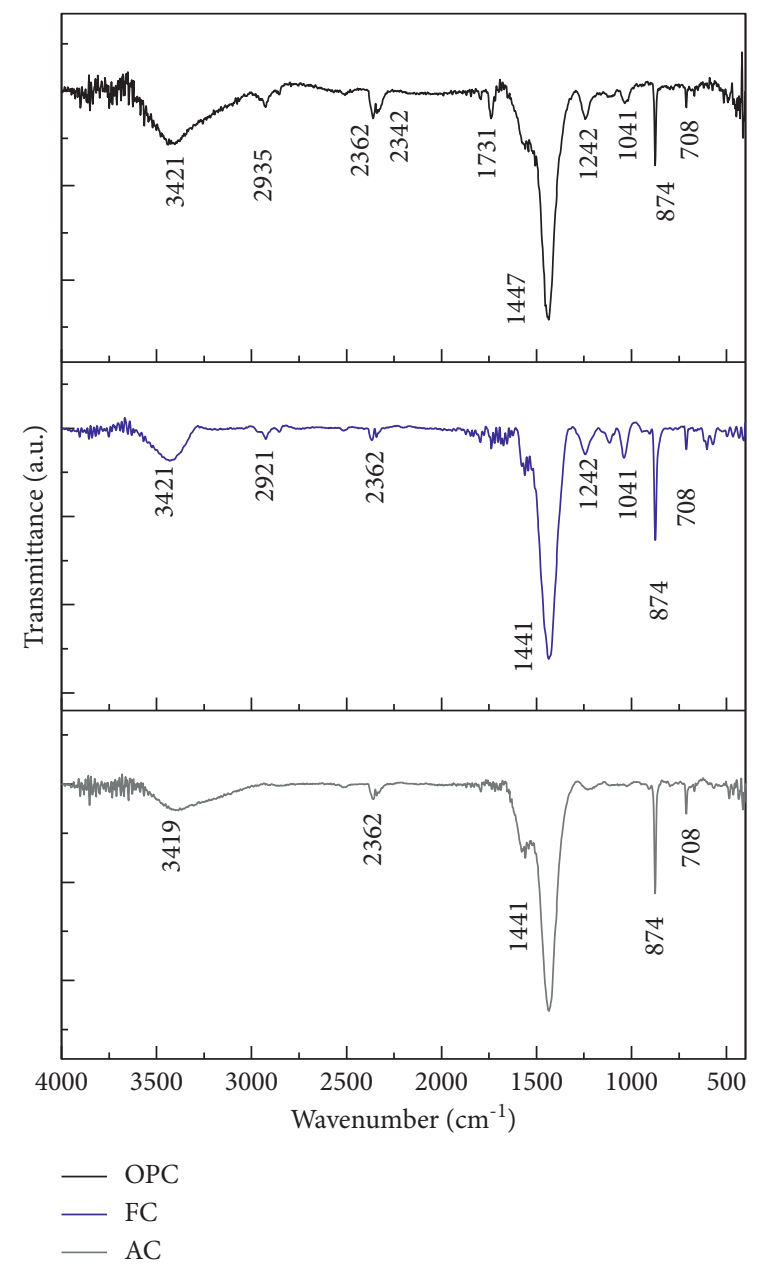

FIGURE 4: FTIR spectra of carbons based on orange peel (OPC), flavedo (FC), and albedo (AC).

difference between the minimum and maximum speed is approximately $12 \mathrm{~F} / \mathrm{g}$.

The calculated capacitances in the samples are within parameters shown at Table 2, where samples of orange peel flavedo and albedo of pomelo are presents, due to which albedo of orange peel has not been used for electrode capacitors. In this way, the importance of this work lies in the fact that there are no reports of obtaining carbon-based orange peel albedo without using activators as a material for anodes in supercapacitors, the proposed method for their production is economical and environment friendly, and the use of nitrogen and was not necessary for mentioning some advantages in comparison of this work, and the alternatives of these subproducts are generated in big amounts in juice industries. 


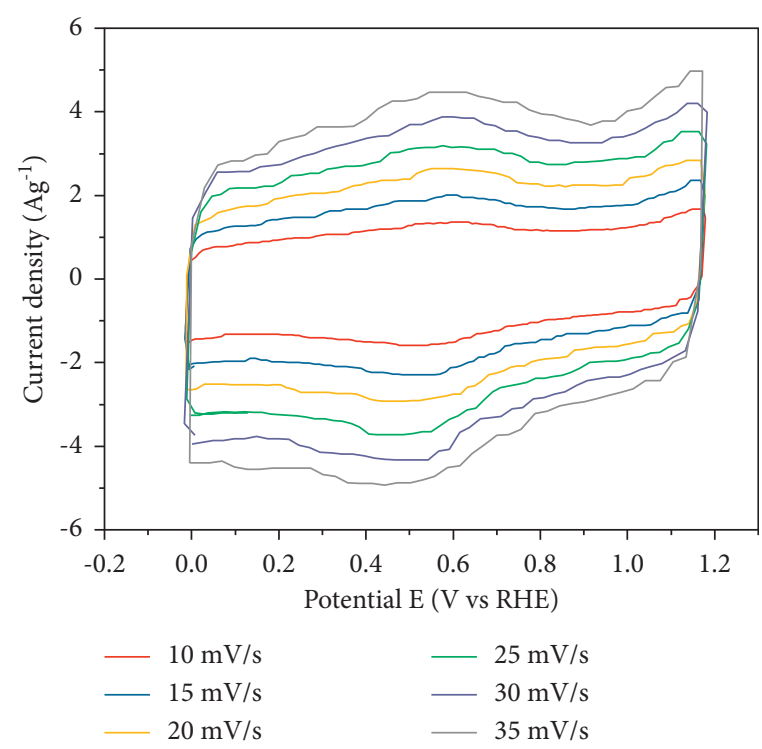

(a)

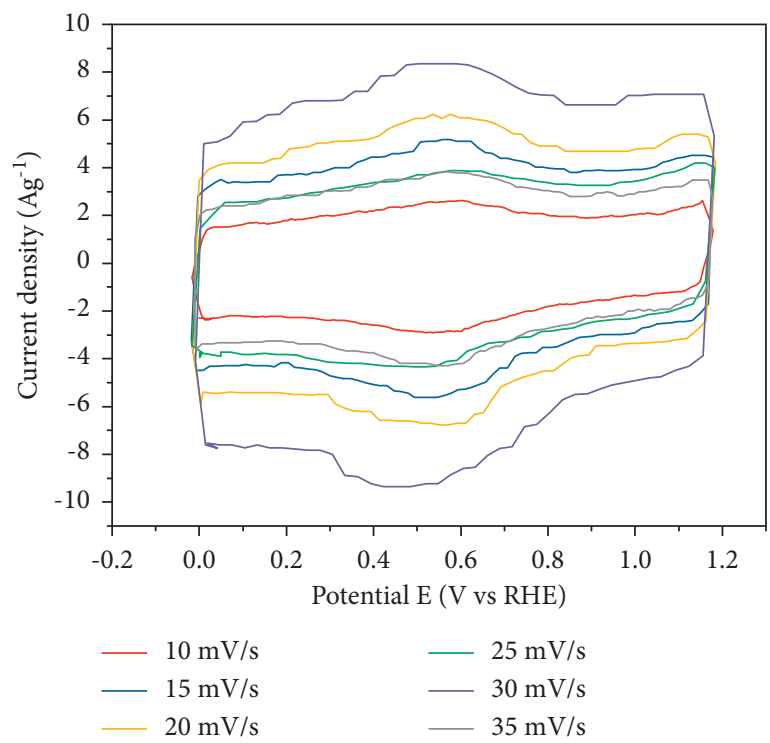

(c)

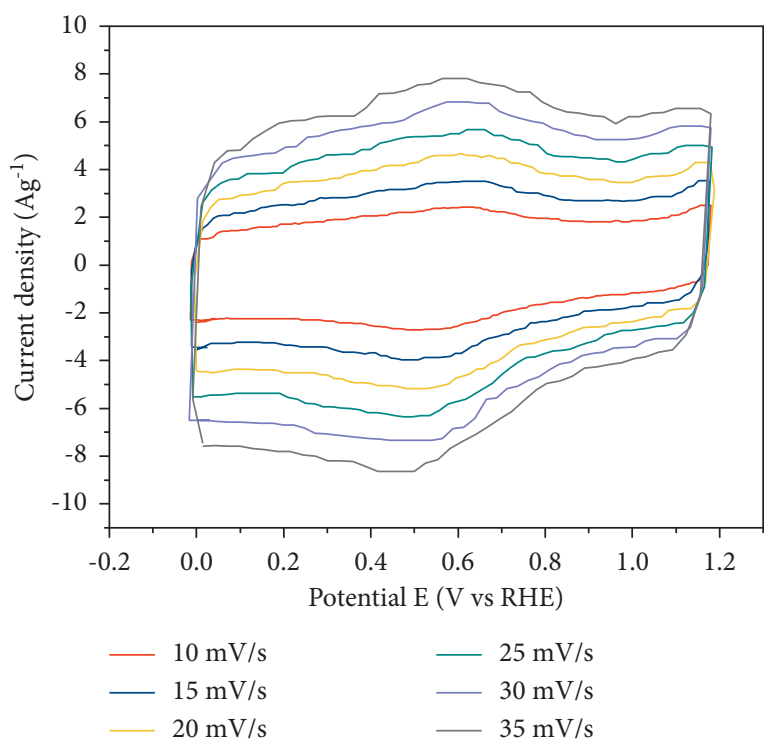

(b)

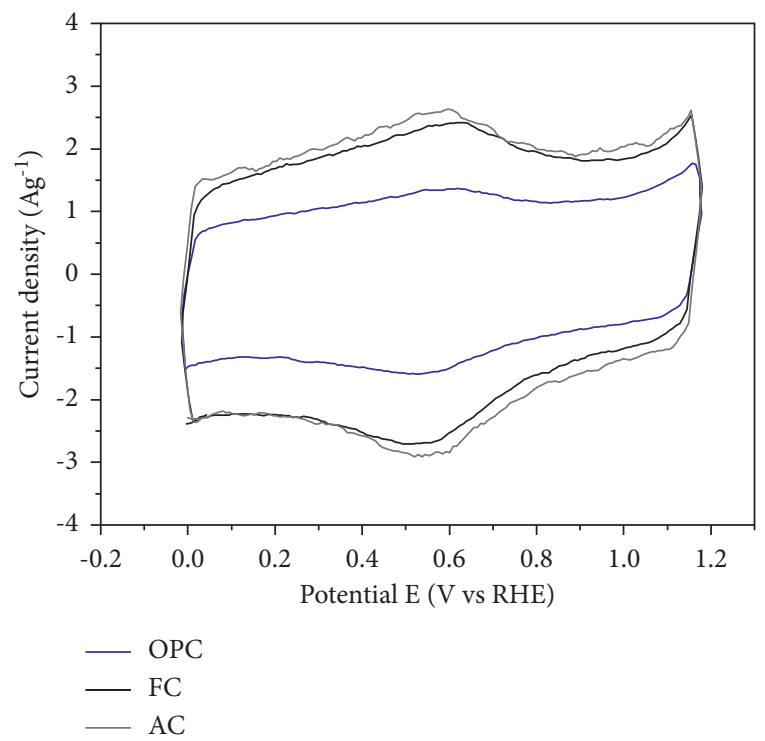

(d)

FIGURE 5: Cyclic voltammetry of (a) OPC, (b) FC, (c) AC, and (d) all samples at $10 \mathrm{mV} / \mathrm{s}$.

The Nyquist diagrams generated from the EIS are shown in Figure 7. The diagrams of the three materials have a similar shape, with no defined semicircles in the high-frequency zone but curves with a tendency to be straight. In high-frequency areas, the absence of semicircles is characteristic of porous carbons, whose charge transfer resistance is minimal [51]. This behavior is related to the easy accessibility of the electrolyte and the electronic transfer through the wide pore fraction [52]. The degree of inclination of the lines is associated with ion diffusion [49]. The inclinations (slopes) of the peel and flavedo curves are close to $45^{\circ}$, while in the albedo, the inclination is close to $90^{\circ}$, which is characteristic of an ideal capacitor [53], which outlines it as the best material of the three studied for supercapacitor applications. The graph shows clearly that the AC presents a steeper slope, traduced as better behavior electrochemical for supercapacitors. 


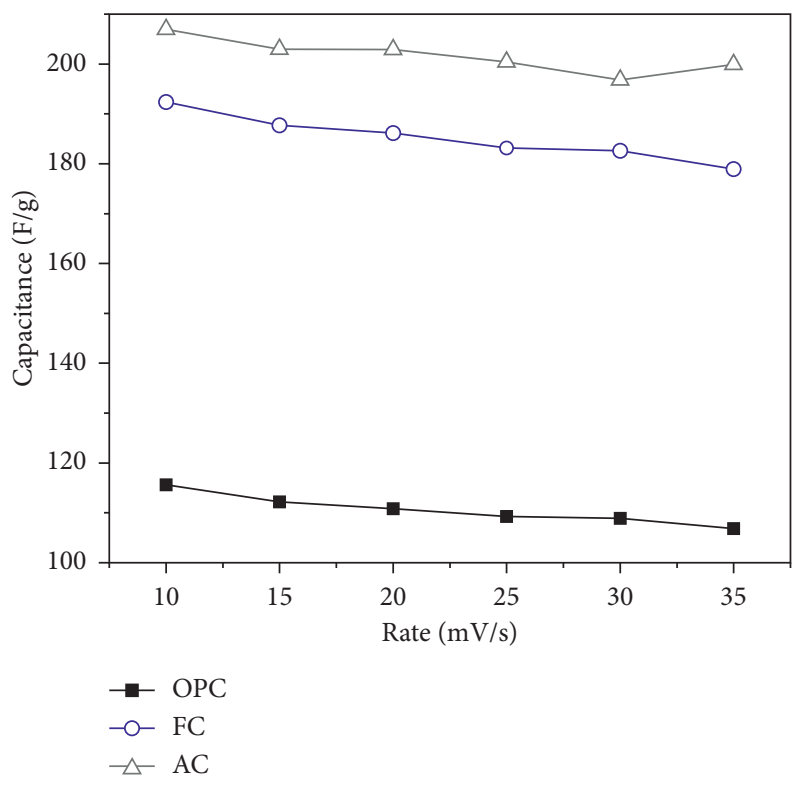

FiguRE 6: Graph of specific capacitance of OPC, FC, and AC concerning scanning speed.

TABLE 2: Capacitances of other works and this work about parts of orange peel.

\begin{tabular}{lcccc}
\hline Carbon source & Electrolyte & $\begin{array}{c}\text { Specific capacitance } \\
(\mathrm{F} / \mathrm{g})\end{array}$ & $\begin{array}{c}\text { Current density (A/g) or sweep velocity } \\
(\mathrm{mV} / \mathrm{s})\end{array}$ & Reference \\
\hline Flavedo doped with $\mathrm{N}_{2}$ and activated with & $0.5 \mathrm{~mol} / \mathrm{L}$ & 92 & $30 \mathrm{mV} / \mathrm{s}$ & {$[17]$} \\
$\mathrm{H}_{3} \mathrm{PO}_{4}$ & $\mathrm{H}_{3} \mathrm{PO}_{4}$ & & & $30 \mathrm{mV} / \mathrm{s}$ \\
Flavedo doped with $\mathrm{N}_{2}$ and activated with & $0.5 \mathrm{~mol} / \mathrm{L} \mathrm{HCl}$ & 28 & $30 \mathrm{mV} / \mathrm{s}$ & {$[17]$} \\
$\mathrm{HCl}$ & $\begin{array}{c}0.5 \mathrm{~mol} / \mathrm{L} \\
\text { Flavedo doped with } \mathrm{N}_{2} \text { and activated with }\end{array}$ & 88 & $0.5 \mathrm{~A} / \mathrm{g}$ & {$[17]$} \\
$\mathrm{H}_{2} \mathrm{SO}_{4}$ & $2 \mathrm{SO}$ & & {$[19]$} \\
\hline Albedo pomelo doped with $\mathrm{N}_{2} \mathrm{PMC}$ & $2 \mathrm{~mol} / \mathrm{L} \mathrm{KOH}$ & 245 & & \\
\hline
\end{tabular}

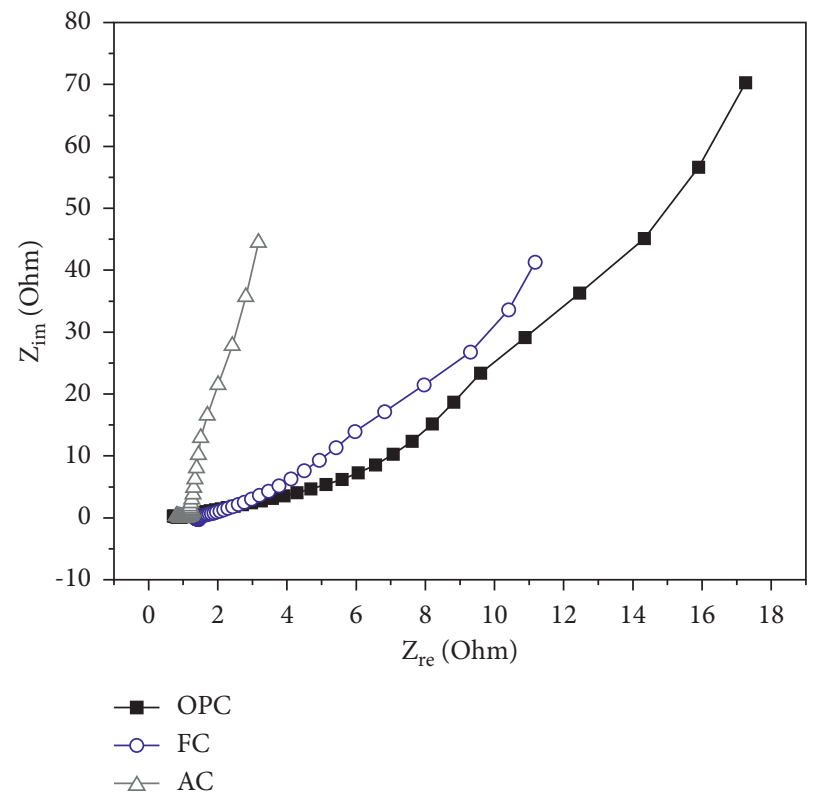

FIgURE 7: Nyquist diagram of OPC, FC, and AC. 


\section{Conclusions}

This work compared the carbons synthesized from complete orange peel, albedo, and flavedo for applications in supercapacitors. SEM tests show that all carbons obtained from the complete peel, albedo, and flavedo showed characteristic rigid and porous structures. The material presented calcium carbonate incrustations from the pyrolysis reactions obtained at high temperatures. The structural analysis and electrochemical behavior showed that the three types of carbon presented capacitance properties, associated with the rapid diffusion of ions and low charge transfer resistance, attributed to their crystalline structure. The carbon obtained from the albedo showed the best properties as a capacitor.

\section{Data Availability}

Data are available on request.

\section{Conflicts of Interest}

The authors declare no conflicts of interest regarding the publication of this paper.

\section{Acknowledgments}

The authors thank Universidad Autónoma de Tamaulipas for the financial support.

\section{References}

[1] International-U.S., "Energy information administration (EIA)," 2021, https:/www.eia.gov/international/analysis/ country/MEX.

[2] S. Huang, X. Zhu, S. Sarkar, and Y. Zhao, "Challenges and opportunities for supercapacitors," APL Materials, vol. 7, no. 10, pp. 1-9, 2019.

[3] L. L. Zhang and X. S. Zhao, "Carbon-based materials as supercapacitor electrodes," Chemical Society Reviews, vol. 38, no. 9, pp. 2520-2531, 2009.

[4] Z. S. Iro, C. Subramani, and S. S. Dash, "A brief review on electrode materials for supercapacitor," International Journal of Electrochemical Science, vol. 11, no. 12, pp. 10628-10643, 2016.

[5] S. T. Senthilkumar, B. Senthilkumar, S. Balaji, C. Sanjeeviraja, and R. Kalai Selvan, "Preparation of activated carbon from sorghum pith and its structural and electrochemical properties," Materials Research Bulletin, vol. 46, no. 3, pp. 413-419, 2011.

[6] Y. Lv, L. Gan, M. Liu et al., "A self-template synthesis of hierarchical porous carbon foams based on banana peel for supercapacitor electrodes," Journal of Power Sources, vol. 209, pp. 152-157, 2012.

[7] Y.-Y. Wang, B.-H. Hou, H.-Y. Lü, C.-L. Lü, and X.-L. Wu, "Hierarchically porous N-doped carbon nanosheets derived from grapefruit peels for high-performance supercapacitors," Chemistry Select, vol. 1, no. 7, pp. 1441-1447, 2016.

[8] Secretaría de información agroalimentaria y pesquera, Ciudad de México, México City, Mexico, Panorama agroalimentario 2020, 2020.
[9] Food and Agriculture Organization of the United Nations (FAO), "Citrus: world markets and trade," pp. 1-13, 2017, https://apps.fas.usda.gov/psdonline/circulars/Citrus.pdf.

[10] L. De Medina-Salas, M. R. Giraldi-Díaz, E. Castillo-González, and L. E. Morales-Mendoza, "Valorization of orange peel waste using precomposting and vermicomposting processes," Sustainable Times, vol. 12, no. 18, pp. 6-8, 2020.

[11] A. A. Arie, H. Kristianto, M. Halim, and J. K. Lee, "Synthesis and modification of activated carbon originated from Indonesian local orange peel for lithium ion capacitor's cathode," Journal of Solid State Electrochemistry, vol. 21, no. 1, pp. 1331-1342, 2016.

[12] L. Wan, D. Chen, J. Liu et al., "Facile preparation of porous carbons derived from orange peel via basic copper carbonate activation for supercapacitors," Journal of Alloys and Compounds, vol. 823, no. 1, pp. 153747-153758, 2020.

[13] S. Ahmed, M. Rafat, and A. Ahmed, "Nitrogen doped activated carbon derived from orange peel for supercapacitor application," Advances in Natural Sciences: Nanoscience and Nanotechnology, vol. 9, no. 3, pp. 1-9, 2018.

[14] S. Kaipannan and S. Marappan, "Fabrication of 9.6 V highperformance asymmetric supercapacitors stack based on nickel hexacyanoferrate-derived $\mathrm{Ni}(\mathrm{OH})_{2}$ nanosheets and bio-derived activated carbon," Scientific Reports, vol. 9, no. 1, pp. 1-14, 2019.

[15] Q. Wei, Z. Chen, Y. Cheng, X. Wang, X. Yang, and Z. Wang, "Preparation and electrochemical performance of orange peel based-activated carbons activated by different activators," Colloids and Surfaces A: Physicochemical and Engineering Aspects, vol. 574, no. 5, pp. 221-227, 2019.

[16] L. Izquierdo and J. M. Sendra, "Citrus fruits| composition and characterization," Encyclopedia of Food Sciences and Nutrition, no. 1986, pp. 1335-1341, 2003.

[17] M. Devendran, "Preparation of chemically modified porous carbon networks derived from Citrus sinensis flavedos as electrode material for supercapacitor," International Journal of Electrochemical Science, vol. 15, no. 1, pp. 4379-4387, 2020.

[18] C. Wang, Y. Xiong, H. Wang, and Q. Sun, "All-round utilization of biomass derived all-solid-state asymmetric carbonbased supercapacitor," Journal of Colloid and Interface Science, vol. 528, no. 1, pp. 349-359, 2018.

[19] H. Peng, G. Ma, K. Sun, Z. Zhang, Q. Yang, and Z. Lei, "Nitrogen-doped interconnected carbon nanosheets from pomelo mesocarps for high performance supercapacitors," Electrochimica Acta, vol. 190, no. 1, pp. 862-871, 2016.

[20] N. Zhao, L. Deng, D. Luo, S. He, and P. Zhang, "Oxygen doped hierarchically porous carbon for electrochemical supercapacitor," International Journal of Electrochemical Science, vol. 13, no. 11, pp. 10626-10634, 2018.

[21] L. S. Mackenzie, H. Tyrrell, R. Thomas, A. S. Matharu, J. H. Clark, and G. A. Hurst, "Valorization of waste orange peel to produce shear-thinning gels," Journal of Chemical Education, vol. 96, no. 12, pp. 3025-3029, 2019.

[22] C. K. Poh, S. H. Lim, H. Pan, J. Lin, and J. Y. Lee, "Citric acid functionalized carbon materials for fuel cell applications," Journal of Power Sources, vol. 176, no. 1, pp. 70-75, 2008.

[23] K. Dujearic-Stephane, P. Panta, Y. M. Shulga, A. Kumar, M. Gupta, and Y. Kumar, "Physico-chemical characterization of activated carbon synthesized from Datura metel's peels and comparative capacitive performance analysis in acidic electrolytes and ionic liquids," Bioresource Technology Reports, vol. 11, no. 1, Article ID 100516, 2020.

[24] M. Rajesh, R. Manikandan, S. Park et al., "Pinecone biomassderived activated carbon: the potential electrode material for 
the development of symmetric and asymmetric supercapacitors," International Journal of Energy Research, vol. 44, no. 11, pp. 8591-8605, 2020.

[25] D. Liu, Y. Wang, Z. Qiu et al., "Porous carbons derived from waste printing paper for high rate performance supercapacitors in alkaline, acidic and neutral electrolytes," RSC Advances, vol. 8, no. 8, pp. 3974-3981, 2018.

[26] A. K. Sharma and Y. Sharma, "Pseudo capacitive studies of polyaniline-carbon nanotube composites as electrode material for supercapacitor," Analytical Letters, vol. 45, no. 14, pp. 2075-2085, 2012.

[27] H.-S. Oh, K. H. Lim, B. Roh, I. Hwang, and H. Kim, "Corrosion resistance and sintering effect of carbon supports in polymer electrolyte membrane fuel cells," Electrochimica Acta, vol. 54, no. 26, pp. 6515-6521, 2009.

[28] A. A. Ensafi, N. Ahmadi, and B. Rezaei, "Electrochemical preparation and characterization of a polypyrrole/nickelcobalt hexacyanoferrate nanocomposite for supercapacitor applications," RSC Advances, vol. 5, no. 111, pp. 91448-91456, 2015.

[29] Y. Cao, K. Wang, X. Wang et al., "Hierarchical porous activated carbon for supercapacitor derived from corn stalk core by potassium hydroxide activation," Electrochimica Acta, vol. 212 , pp. 839-847, 2016.

[30] R. H. Hesas, A. Arami-Niya, W. M. Ashri, W. Daud, and J. N. Sahu, "Preparation and characterization of activated carbon from apple waste by microwave-assisted phosphoric acid activation: application in methylene blue adsorption," BioResources, vol. 2, no. 2, pp. 2950-2966, 2013.

[31] S. Wang, C. Wang, and X. Ji, "Towards understanding the saltintercalation exfoliation of graphite into graphene," RSC Advances, vol. 7, no. 82, pp. 52252-52260, 2017.

[32] S. Yaragalla, R. Mishra, S. Thomas, N. Kalarikkal, and H. J. Maria, Carbon-based Nanofillers and Their Rubber Nanocomposites, Elsevier, Amsterdam, Netherlands, 2018.

[33] C. Liang, Y. Chen, M. Wu et al., "Green synthesis of graphite from $\mathrm{CO}_{2}$ without graphitization process of amorphous carbon," Nature Communications, vol. 12, no. 1, pp. 1-9, 2021.

[34] J. Xiang, W. Lv, C. Mu, J. Zhao, and B. Wang, "Activated hard carbon from orange peel for lithium/sodium ion battery anode with long cycle life," Journal of Alloys and Compounds, vol. 701, pp. 870-874, 2017.

[35] I. Rianasari, F. Benyettou, S. K. Sharma, T. Blanton, S. Kirmizialtin, and R. Jagannathan, "A chemical template for synthesis of molecular sheets of calcium carbonate," Scientific Reports, vol. 6, no. 1, Article ID 25393, 2016.

[36] K. Y. Chong, C. H. Chia, and S. Zakaria, "Polymorphs calcium carbonate on temperature reaction," AIP Conference Proceedings, vol. 1614, no. 1, pp. 52-56, 2014.

[37] X. Luo, X. Song, Y. Cao, L. Song, and X. Bu, "Investigation of calcium carbonate synthesized by steamed ammonia liquid waste without use of additives," RSC Advances, vol. 10, no. 13, pp. 7976-7986, 2020.

[38] A. Lesbani, P. Tamba, R. Mohadi, and F. Fahmariyanti, "Preparation of calcium oxide from Achatina fulica as catalyst for production of biodiesel from waste cooking oil," Indonesian Journal of Chemistry, vol. 13, no. 2, pp. 176-180, 2013.

[39] A. Samanta, D. K. Chanda, P. S. Das, J. Ghosh, A. K. Mukhopadhyay, and A. Dey, "Synthesis of nano calcium hydroxide in aqueous medium," Journal of the American Ceramic Society, vol. 99, no. 3, pp. 787-795, 2016.

[40] K. Sawada, "The mechanisms of crystallization and transformation of calcium carbonates," Pure and Applied Chemistry, vol. 69, no. 5, pp. 921-928, 1997.
[41] J. V. Rau, S. N. Cesaro, D. Ferro, S. M. Barinov, and I. V. Fadeeva, "FTIR study of carbonate loss from carbonated apatites in the wide temperature range," Journal of Biomedical Materials Research, vol. 71B, no. 2, pp. 441-447, 2004.

[42] V. Sahu, S. Shekhar, P. Ahuja et al., "Synthesis of hydrophilic carbon black; Role of hydrophilicity in maintaining the hydration level and protonic conduction," RSC Advances, vol. 3 , no. 12, pp. 3917-3924, 2013.

[43] S. Kamsonlian, S. Suresh, C. B. Majumder, and S. Chand, "Characterization of banana and orange peels: biosorption mechanism," International Journal of Services Technology and Management, vol. 2, no. 4, pp. 1-7, 2011.

[44] J. Yang and K. Qiu, "Preparation of activated carbons from walnut shells via vacuum chemical activation and their application for methylene blue removal," Chemical Engineering Journal, vol. 165, no. 1, pp. 209-217, 2010.

[45] M. S. Shamsuddin, N. R. N. Yusoff, and M. A. Sulaiman, "Synthesis and characterization of activated carbon produced from kenaf core fiber using $\mathrm{H} 3 \mathrm{PO} 4$ activation," Procedia Chemistry, vol. 19, no. 1, pp. 558-565, 2016.

[46] C.-H. Yang, Q. D. Nguyen, T.-H. Chen, A. S. Helal, J. Li, and J.-K. Chang, "Functional group-dependent supercapacitive and aging properties of activated carbon electrodes in organic electrolyte," ACS Sustainable Chemistry \& Engineering, vol. 6, no. 1, pp. 1208-1214, 2018.

[47] Y. He, Y. Zhang, X. Li et al., "Capacitive mechanism of oxygen functional groups on carbon surface in supercapacitors," Electrochimica Acta, vol. 282, no. 1, pp. 618-625, 2018.

[48] E. Frackowiak and F. Béguin, "Carbon materials for the electrochemical storage of energy in capacitors," Carbon, vol. 39, no. 6, pp. 937-950, 2001.

[49] C. K. Ranaweera, P. K. Kahol, M. Ghimire, S. R. Mishra, and R. K. Gupta, "Orange-peel-Derived carbon: designing sustainable and high-performance supercapacitor electrodes," Journal of Carbon Research, vol. 3, no. 25, pp. 1-17, 2017.

[50] X.-r. Li, Y.-h. Jiang, P.-z. Wang et al., "Effect of the oxygen functional groups of activated carbon on its electrochemical performance for supercapacitors," New Carbon Materials, vol. 35, no. 3, pp. 232-243, 2020.

[51] J. Yan, T. Wei, B. Shao et al., "Preparation of a graphene nanosheet/polyaniline composite with high specific capacitance," Carbon, vol. 48, no. 2, pp. 487-493, 2010.

[52] S. Saha and T. Kuila, "Part 3 Supercapacitor: nanostructured carbon-based electrodes for supercapacitor applications," in Nanomaterials for Electrochemical Energy Storage DevicesScrivener Publishing, Beverly, MA, USA, 2020.

[53] P. L. Taberna, P. Simon, and J. F. Fauvarque, "Electrochemical characteristics and impedance spectroscopy studies of carbon-carbon supercapacitors," Journal of the Electrochemical Society, vol. 150, no. 3, p. A292, 2003. 